\title{
Selection of Suitable Safety Activities and Experience of Safety Condition Establishment
}

\author{
Akihiko Hidaka, Atsumi Miyake \\ Graduate School of Environment and Information Sciences, Yokohama National University, Yokohama, Japan \\ Email: akihiko hidaka@plamatels.co.jp
}

Received 21 January 2015; accepted 9 February 2015; published 11 February 2015

Copyright (C) 2015 by authors and Scientific Research Publishing Inc.

This work is licensed under the Creative Commons Attribution International License (CC BY). http://creativecommons.org/licenses/by/4.0/

(c) (i) Open Access

\begin{abstract}
In recent years, Japanese manufacturing firms have been building factories in the developing countries of Southeast Asia and employing local personnel. Using local employees who were basically people of the agricultural countries implies difficulties in both technical and safety terms. This study examines how quickly and effectively the companies going into the developing countries establish a standard of safety. The authors focus on Vietnam and Thailand as representative countries. To their surprise, the authors find that all 27 companies that answered their questionnaire had introduced " $5 S$ activities" at startup and were continuing to use them. In addition, nearly $80 \%$ of the companies began using "KY activities", "Safety proposal activities", and "Examinations of accidents" soon after startup. One of the authors Akihiko Hidaka, when serving as the president of the Thai subsidiary of a Japanese chemical company, developed safety activities to reduce workrelated accidents. And he knew that the kinds of safety activities he developed were same as above 4 activities. So he evaluated these activities and judged them to be effective. The authors conclude that "5S activities", "KY activities", "Safety proposal activities", and "Examinations of accidents" were the activities best able to improve safety effectively and quickly in developing countries. The authors describe the safety activities carried out at the Thai company and then describe the most important features of the methods used to establish safety conditions at the firm.
\end{abstract}

\section{Keywords}

Safety Activity, Developing Countries, East Asian Country, 5S Activity, KY Activity, Safety Proposal Activity, Examinations of Accidents

\section{Introduction}

For 30 years, Akihiko Hidaka worked at a major Japanese chemical company, focusing mainly on the manufacturing and research and development aspects of synthetic resin. Many changes in technology and business prac- 
tices occurred during that period. In the latter years, many Japanese companies relocated outside the country, for two main reasons. First, both labor and construction costs were lower elsewhere in East Asia; second, relocation increased the size of the market and potential consumers at a time when the demand for synthetic resin in Japan was diminishing. Hidaka's company participated in this shift in manufacturing, and the author spent the second half of his professional career as the president of its Thai subsidiary. It had 150 employees and focused on the coloring and compounding of resin as well as marketing it to consumers in Southeast Asia. As the firm's only Japanese technical personnel, the author's duties ranged from overseeing production, technical operations, and quality control of products, facility maintenance, security management, hygiene supervision, and accident prevention.

Despite relocating to developing country, all manufacturing firms [1] [2] should maintain safety. This paper examines how to establish a safety system or standard by which safety conditions can be ensured quickly and effectively.

This paper seeks to select the most effective and suitable safety activity by investigating the activities Japanese-affiliated companies operating in developing countries adopted when first established, using Thailand and Vietnam as representative nations. A questionnaire survey on safety was conducted on the managers of Japanese subsidiary companies located in these two developing countries. Using the survey results and the author's Thai experience, the authors selected the safety activities required in the factories of developing countries as well as the most effective ways of introducing them and some other key points about them.

\section{Questionnaire for Japanese Companies in Thailand and Vietnam}

\subsection{Contents of the Questionnaire}

1) What is the safety level of your parent company?
$\begin{array}{llllll}5 & 4 & 3 & 2 & 1 & \text { (5: Superior }\end{array}$
3: Industry average $\quad 1$ : Too low)

2) What is the safety level of your company located in Southeast Asia?
$\begin{array}{llllll}5 & 4 & 3 & 2 & 1 & \text { (5: Superior }\end{array}$
3: Industry average
1: Too low)

3) What safety activity has your company adopted? If your company is using several activities, please check all of them.
a) 5 activity (including $3 S$ and $6 S$ )
※1) Adopted Not adopted
b) KY (including KYT)
c) Shisa Kosyou (point and call)
※2) Adopted
Not adopted
d) HHK (Hiyari-Hatto Teian)
Adopted Not adopted
e) Safety proposal activity
※3) Adopted Not adopted
f) Examination of accidents
Adopted
Not adopted
g) OHSMS
Adopted Not adopted
h) An activity other than the above a) - g)
Adopted Not adopted
Adopted Not adopted

If you have chosen $h$ ), please fill out the following columns:

※1) "Arrangement" "Put into order" "Cleaning" "Sanitary" "Discipline"

$※ 2$ ) Hazard prediction

※3) A proposal activity: fill in what you felt a shiver or anxious about

4) Please indicate when the activities identified above began, in chronological order.

(Please indicate using the item numbers above, starting with the earliest)
$(\quad) \rightarrow(\quad) \rightarrow(\quad) \rightarrow(\quad) \rightarrow(\quad) \rightarrow(\quad) \rightarrow(\quad) \rightarrow(\quad)$

5) Please indicate if there are ongoing activities to improve safety at your factory.

\subsection{Results of the Questionnaire}

1) The evaluation results for the safety levels of the each parent company of subsidiaries in Thailand or Vietnam (Table 1).

2) The evaluation results for the safety levels of the subsidiary companies in Thailand or Vietnam (Table 2).

The evaluation results for the safety levels of the each parent company of subsidiaries in Thailand or Vietnam appear in Table 1. For both Thailand and Vietnam, the average value is nearly 4. In the result for his own subsidiary company, seen in Table 2, the average value is nearly 3 . Thus, the management of a Japanese company 
Table 1. The safety levels of the each parent company (the number of the company).

\begin{tabular}{cccccc}
\hline Level of Safety & Rank 5 & Rank 4 & Rank 3 & Rank 2 & Rank 1 \\
\hline Thailand & 2 & 8 & 4 & 0 & 0 \\
Vietnam & 4 & 4 & 5 & 0 & 0 \\
\hline
\end{tabular}

Rank 5: superior, rank 3: industry average, rank 1: too low.

Table 2. The safety level of each subsidiary company (the number of the company).

\begin{tabular}{cccccc}
\hline Level of Safety & Rank 5 & Rank 4 & Rank 3 & Rank 2 & 1 \\
Thailand & 0 & 3 & 10 & 3 & 4 \\
Vietnam & 3 & 3 & 3 & 0 \\
\hline
\end{tabular}

Rank 5: superior, rank 3: industry average, rank 1: too low.

located in developing countries striving to improve safety judged that the safety level of his own company was one degree lower than that of his parent. However, the new subsidiary had also managed to improve safety to within only one degree of the parent, which had a longer history and consisted entirely of Japanese employees. The author was proud of this achievement.

3) Safety activities adopted by companies in developing countries.

Table 3 summarizes the responses given by 14 Thai and 13 Vietnamese companies.

This surprising result shows that all of the 27 Thai and Vietnamese companies that answered the questionnaire adopted "5S activities" [3] [4]. The fact that the Japanese companies adopted "5S activities" was very significant, as are the directionalities. Many companies also adopted "Safety proposal activity" and "Examinations of accidents". The former was adopted by all 14 Thai companies and nine Vietnamese companies, a total of 85\% of all firms. "Examinations of accidents" was adopted by all 14 Thai companies and nine Vietnamese firms, again a total of 85\%. Next was "KY activities" [5] [6], performed by 11 Thai companies and nine Vietnamese companies, for a total of $74 \%$.

4) The chronological order of safety activity adoption.

Next, the authors examined the safety activities' order of adoption. Native workers were hired when the subsidiaries were established. They were trained first in plant operations and then in safety awareness. Safety activities were adopted in a meaningful sequence. The top managers of newly established companies conduct safety work according to an order that maximizes the profits allowable within their limited time span. They must select the activities that are essential for the native workers to know and that will improve their safety awareness. It is thus important to know the order in which the activities were adopted. The results allow us to plot the order in which safety standards were established.

a) The chronological order of safety activity adoption in the Thai companies.

The chronological order of safety activity adoption in the Thai companies is shown in Table 4. The numbers corresponding to the safety activities are as follows:

1. 5 S activities

2. KY activities

3. Point and call

4. HHK

5. Safety proposal activity

6. Examinations of accidents

7. OHSMS

8. Another activity

As Table 4 shows, one company had no records, and two began all their activities at once. Eleven companies provided the order in which their safety activities began.

Surprisingly, nine companies began with "5S activities". Activities 2, 6, and 5 stand out within third of each company.

b) The chronological order of safety activity adoption in the Vietnamese companies.

Eight Vietnamese companies responded about the order of their activities, shown in Table 5. All responded that " 5 S activities" came first, as with the Thai companies. The importance of " $5 \mathrm{~S}$ activity" thus needs to be understood. 
Table 3. Safety activity adopted by Japanese companies in Thailand and Vietnam.

\begin{tabular}{lcccc}
\hline \multicolumn{1}{c}{ Safety activity } & Thailand & Vietnam & Total & Adoption \% \\
\hline 1. 5S activity & 14 & 13 & 27 & $100 \%$ ※1) \\
2. KY activity & 11 & 9 & 20 & $74 \%$ \\
3. Point and call & 6 & 3 & 9 & $33 \%$ \\
4. HHK & 6 & 7 & 13 & $48 \%$ \\
5. Safety proposal activity & 14 & 9 & 23 & $85 \%$ \\
6. Examinations of accidents & 13 & 10 & 23 & $85 \%$ \\
7. OHSMS & 8 & 1 & 9 & $33 \%$ \\
8. Another activity & 5 & 6 & 11 & $41 \%$ \\
\hline
\end{tabular}

※1) The adoption percentage is based on the total of the two countries.

Table 4. The chronological order of safety activity adoption in the Thai companies.

\begin{tabular}{cl} 
Company name & \multicolumn{1}{c}{ Order of adoption (early $\leftarrow \rightarrow$ late) } \\
\hline A & No record; can't answer (now ongoing: 1, 2, 3, 4, 5, 6, 7) \\
B & All of them started at once 18 years ago (now ongoing: 1, 2, 5, 6, 7) \\
C & $7 \rightarrow 4 \rightarrow 6 \rightarrow 1 \rightarrow 5 \rightarrow 2 \rightarrow 3 \rightarrow 8$ \\
D & $1 \rightarrow 5 \rightarrow 6 \rightarrow 8$ \\
E & All of them started at once 20 years ago (now ongoing: $1,2,5,6,7$ ) \\
F & $1 \rightarrow 2 \rightarrow 3 \rightarrow 5 \rightarrow 4 \rightarrow 6$ \\
G & $1 \rightarrow 6 \rightarrow 6$ \\
H & $1 \rightarrow 6 \rightarrow 2 \rightarrow 7 \rightarrow 5$ \\
I & $1 \rightarrow 6 \rightarrow 5 \rightarrow 7$ \\
J & $1 \rightarrow 5 \rightarrow 6 \rightarrow 2$ \\
K & $1 \rightarrow 2 \rightarrow 6 \rightarrow 4 \rightarrow 5 \rightarrow 3$ \\
L & $1 \rightarrow 2 \rightarrow 6 \rightarrow 5$ \\
M & $2 \rightarrow 3 \rightarrow 4 \rightarrow 5 \rightarrow 6 \rightarrow 1 \rightarrow 7 \rightarrow 8$ \\
N & $1 \rightarrow 2 \rightarrow 5 \rightarrow 6 \rightarrow 8$
\end{tabular}

Table 5. The chronological order of safety activity adoption in the Vietnamese companies.

\begin{tabular}{cl} 
Company name & \\
\hline O & $1 \rightarrow 5 \rightarrow 6$ \\
P & $1 \rightarrow 8 \rightarrow 6 \rightarrow 5 \rightarrow 2 \rightarrow 4$ \\
Q & $1 \rightarrow 2 \rightarrow 4 \rightarrow 8 \rightarrow 6$ \\
R & All of them started at once one year ago (now ongoing: 1, 2, 4, 6, 8) \\
S & $1 \rightarrow 5 \rightarrow 4 \rightarrow 2 \rightarrow 6$ \\
T & All of them started at once one year ago (now ongoing: $1,2,3,4,5,6)$ \\
U & All of them started at once one year ago (now ongoing: $1,2,3,5)$ \\
V & $1 \rightarrow 2 \rightarrow 3$ \\
W & All of them started at once one year ago (now ongoing: 1,6 ) \\
X & $1 \rightarrow 2 \rightarrow 5 \rightarrow 4 \rightarrow 6$ \\
Y & $1,5 \rightarrow 6 \rightarrow 2,4,8 \rightarrow 3 \rightarrow 8$ \\
Z & $1 \rightarrow 5 \rightarrow 2$
\end{tabular}

1) One company didn't describe the order of their activities. 


\section{Selection of Suitable Safety Activities for New Companies in Developing Countries}

The questionnaire results indicate that most of the Thai and Vietnamese companies adopted " 5 S activities" when first established and then introduced "Examinations of accidents”, "Safety proposal activity”, and "KY activities” one after the other. This result reflects Hidaka's management work in Thailand, during which he improved his firm's safety level. The activities he used and their order are nearly as they appear in the survey results.

The questionnaire asked "Please indicate if there are ongoing activities to improve safety at your factory".

Two responses are described below.

1) A Thai company reported that almost no discipline or morale is provided by the parent, which follows something close to a noninterference policy.

2) A Vietnamese company reported that they lack safety awareness. They were trained but did not understand the training. They do their work their own way, which is very dangerous by Japanese standards.

These examples show that it is very difficult for native workers to operate in safe conditions when using the newest equipment and machines at newly established companies. As native employees are from agricultural countries, they are engaging in industrial work for the first time. It is thus important for newly established factories in developing countries to create a system for establishing safe conditions quickly and effectively through suitable safety activities. This study intends to select the most suitable activity.

The most important priority is "5S activities". The new employees of newly established factories have little safety awareness, as they have had no need of one before being hired. They are also undisciplined and do not obey the rules, the most basic requirement of safety, in the authors' view. The basis of the safety culture [7] [8] is this "Obey the rules", which requires discipline. The top managers [9] [10] of developing-nation firms who responded to the questionnaire recognized this lack of discipline and considered it fatal to the establishment of new companies. First, therefore, it was important to begin " $5 \mathrm{~S}$ activities" early in order to educate and discipline and then to build up the organization until its employees were ready to "Obey the rules". "5S Activities" have five behavior standards: "Seiri”, "Seiton", "Seiketsu”, "Seisou”, and "Shitsuke”. As they all begin with "S” we call them the "5S activities". The words mean "Arrangement”, "Put into order”, “Cleaning” "Sanitary”, and "Discipline”, respectively. These standards ask all employees to keep the factory and office clean after examining what needs to be done-for example, around a machine-to achieve that goal and understanding its importance. Through this behavior, the worker acquires discipline. Although this activity doesn't constitute direct action to improve or maintain safety, it teaches the workers about a basic feature of safety awareness; it is a shortcut to safety awareness rather than a practical path to safe behavior.

It is then important to proceed to "Examinations of accidents”, "Safety proposal activity”, and "KY activities”. The safety lessons begun through the " $5 \mathrm{~S}$ activities” can instill a certain degree of discipline, leading to "obeying the rule" and an awareness of safety. Therefore, there is a need for safety education. Employees in the manufacturing industry need to know that they can be injured using machines or through equipment failure. Learning about the reasons for industrial accidents and injuries will help factory workers gain the safety knowledge they need to prevent them. "Examinations of accidents" corresponds to this process [11]. "KY activities (i.e. hazard prediction)” also provide safety education. In this process, employees learn that there is a risk at any location and with any process and then study how to predict hazards and thus prevent accidents. They come to understand that they can eliminate risks through KY activities; they are safety improvement measures based on knowledge. "Safety proposal activity” also improves safety by identifying safety failures, which employees can do after having obtained safety awareness and education. "Safety proposal activity” thus enhances employees' safety environment.

Chemical firms in developing countries must thus foster, first, safety awareness, then safety education, and third, a safety environment in order to improve its safety level rapidly and effectively. "5S activities", "Examinations of accidents”, "KY activities”, and “Safety proposal activity” must thus all be implemented.

\section{Safety Process Establishment Experiences in East Asian Countries}

The experience at a Thai chemical company will now be described. As mentioned, the survey results reflect Hidaka's management experience at the company, which managed to improve its safety level. The firm adopted the activities described in the survey, in nearly the same order. First, Hidaka's Thai firm will be described. 


\subsection{Company Profile and Safety Risk Concerning Factory Work}

1) Company profile

a) The company performed plastic coloring and compounding.

b) The factory mainly produced engineering and multipurpose plastics.

c) The working framework consisted of three groups in two shifts on a rotation basis.

d) The basic raw materials used in the factory were petrochemical resins and additives. The resins were flammable, and the workers handled objects that were as dangerous as the base materials. Thus, there was a high risk of fire. There was also a risk of fine powder explosion because the factory treated the resin powders. The factory used heavy machines (such as the extruder and the tumbler), rotating equipment, and high temperature facilities. Workers risked accidents using this equipment (such as being pinched, trapped, burned, cut, or knocked to the ground).

2) Level of the employees

a) The management, or upper staff, level consisted of university graduates.

b) The factory workers were mostly junior or senior high school graduates.

c) The factory had no maintenance specialists with expertise to repair the equipment or facilities. Thus, all the employees required extensive training.

3) Safety target and method at the Thai factory

a) Target

The target was to bring the employees' safety awareness up to par with that of the employees at the Japanese parent company.

b) Method

The method of improving safety awareness was an orderly, step-by-step process of improving the most important aspect of safety first and then proceeding in order of importance.

\subsection{Safety Activities}

\section{1) The first activity is $5 S$}

All of the employees were trained to understand and use the $5 \mathrm{~S}$ ideas and to thoroughly apply them to all factory processes, from buying basic materials and production of the plastics to delivery of the product to customers. Implementing the 5S activities changed the factory, making it bright and easy to move around in, where problems were easily found and accidents, such as stumbling into someone or dropping something, easily avoided by keeping the factory clean, although polymer powder and coloring agents were still problems. The 5S process also led employees to obey the company's policies and pay attention to safety matters.

a) The first step was translating the concepts of the 5S, explaining them, and educating the employees about them. To this end, employees were given specific examples of usage and activities that demonstrated the concepts [Seiri] (meaning "arrangement") and [Seiton] (meaning "to put into order").

b) Next, $5 \mathrm{~S}$ committee member from each section and from among the employees were selected. The $5 \mathrm{~S}$ committee was tasked with choosing the target and plan of action. It was important that $5 \mathrm{~S}$ activities be promoted not only by top-down policies but also by the bottom-up activities of the $5 \mathrm{~S}$ committee. Committee members were selected from all sections, including the staff section of the office. The 5S committee promoted many safety activities, such as writing the $5 \mathrm{~S}$ patrol plan for monitoring $5 \mathrm{~S}$ conditions, evaluating the plan, and commending those groups that show good results. These tasks were performed using a rally process called the " $5 \mathrm{~S}$ rally" in which groups competed against each other to win evaluation point for their activities.

c) Third, management patrolled the factory area to verify the results of the 5S implementation and the 5S committee's work. Those in charge in each section coached their members and evaluated the $5 \mathrm{~S}$ level of their section and were responsible for the success of their group.

d) As the firm president, Hidaka patrolled the entire factory area. During one patrol, he photographed a 5S failure, printed the photos, and distributed copies around the factory to let the employees know what to avoid and to educate them in order to help them achieve the safety level the author demanded.

e) Despite the daily 5S activities, dirt and dust accumulated in the factory; for instance, there was dust or cobwebs at the high points that could not be reached by hand. To remedy this problem, the firm held major semiannual cleaning events in which factory operations were halted while the members cleaned the factory premises. The factory was divided into 20 areas, the office into 10, and the warehouse and waste facility into 30 
areas. Each group cleaned its area all day. At the end of the day, the group leaders patrolled and checked all the areas. In this significant 5S event, called the "Big Cleaning Day", everyone attains a sense of achievement by cooperating. When employees assessed the status of each area, they were reassured about their $5 \mathrm{~S}$ standards. Thus, Big Cleaning Day was fruitful in many ways.

\section{2) KY: an important activity}

The KY process, in which K stands for kiken (“danger”) and Y for yochi ("provision”), is a well-known practice in Japan. The firm believed that it was very important that all employees understood its meaning, kept it in mind, and applied it.

a) First, we taught $\mathrm{KY}$

First, the firm taught KY to the leader class member. Next, it taught group KY to the working groups. This group KY, called "KYT", is a group training method used to teach $\mathrm{KY}$ concepts and train employees in its methods.

b) At the beginning of the KY activity, a KY training sheet was used in every operational group as a way to practice the identification of a danger, determine its importance, and consider possible countermeasures using the KYT method. During this training, the firm recorded the names of all participating employees or used a KY CARD in which the group members described the results of $\mathrm{KY}$ activities in order to confirm that all workers were participated in the training.

\section{3) Examinations of accidents}

Early on, the firm implemented examinations of accidents at the Japanese parent company and how they had been handled to prevent similar accidents at the Thai factory. Focusing on rotating material and compounding factory accidents, employees studied data on their causes and considered prevention methods. This activity required translating the accident reports from Japanese into English and then into Thai.

\subsection{Evaluation of the Results of These Safety Activities}

1) The safety policy

The firm's safety policy should be posted at the office, in the meeting room, and in the control room. There should be occasional training sessions in which the policy is explained and the employees educated on it. Participating in $5 \mathrm{~S}$ and $\mathrm{KY}$ training sessions will help employees understand the implementation and spirit of the policy.

\section{2) 5 S activity}

The Thai employees understood the purposes of the $5 \mathrm{~S}$ activity and what it required of them, and every representative of every section had worked with the $5 \mathrm{~S}$ committee. The Safety Officer managed the committee, and the committee (comprising 15 representatives of each section) formulated the annual plan. Once the plan was in place, the monthly safety targets were determined at the monthly meetings.

a) At the monthly meetings, the responsible person reported on any countermeasures for the problems identified by the $5 \mathrm{~S}$ patrol the previous month. After reviewing these reports, they confirmed the important target for the current month and then patrolled in two or three groups. b) The patrol member marked with red paper the location or piece of equipment that the $5 \mathrm{~S}$ patrol had indicated was problematic. c) After finishing the patrol, members discussed these trouble points and chose countermeasures with members of the responsible section. d) Twice a year, the group and employee with the best $5 \mathrm{~S}$ records were selected for an award. The monthly meetings, patrols, group and individual evaluations, and semiannual selection of group and individual awards were faithfully repeated. The $5 \mathrm{~S}$ committee members were rotated each year to reduce the top-down pressure exerted by taking direct charge of the $5 \mathrm{~S}$ work. As mentioned, the compounding factory was dirty because of the powdery nature of the coloring agent, the plastic snips that accumulate, and the scattering of plastic pellets. It is challenging to maintain a clean and safe work environment. However, Hidaka strongly believes that the effective management of any factory begins with cleanliness, which is also necessary for increasing safety levels. Cleanliness was very effective for another reason, as indicated by the term [shitsuke] ("well-bred"). Moreover, the 5S activities improved the quality of the firm's plastic pellets, which, in turn, helped improve the customers' confidence in the quality of all the firm's products. In the compounding process, it was difficult to prevent contaminating the powder with another type of resin, burnt resin, or waste. Success was achieved by applying $5 S$ in the same direction as the activity used to prevent the contamination of the pellets. The result was that maintaining good 5S conditions contributed to resuming ties with Japanese automobile parts makers that expected the firm's products to be extremely high quality. 
3) KY activity

All the Thai employees were able to understand the concepts of KY through explanations and education. However, as the firm used readymade training sheets, the training was quite different from the actual processes. Moreover, because the KYT method is a group method, the firm was unable to assess employees' knowledge at the individual level. Therefore, this method is suitable for studying the effectiveness only of KYT because the employees consider only one theme as a group. However, it is inadequate for evaluating the effectiveness of individuals. Thus, individual KY effectiveness cannot be assessed nor the accident prevention levels evaluated. This is a problem even in Japan and is quite difficult to solve. However, it must be addressed, even at the Thai factory.

4) Examinations of other accidents

The Thai compounding factory performed [examinations of in-house accidents]. After eliminating the accidents that were too dissimilar to be helpful, a series of worker accidents was chosen as teaching material. First, Hidaka translated the Japanese accident reports into English, and then the Safety Officer translated them into Thai. Then, the Thai reports were distributed to each group. The place and timing of the study sessions were different for each group, but they all examined the reports at their safety meetings as a safety topic. They examined another case during the meeting of shift workers, also as a safety topic. These study activities started with the translation of an accident report. Hidaka immediately addressed cases of accidents that could have occurred at the Thai factory (e.g., cases of pinching or being trapped) and requested an intensive examination of the case. This educational material indicated to the Thai employees the types of safety problems and accidents that occurred in the Japanese parent company or in the worldwide group company, the types of problems that needed to be eliminated, and the measures required to eliminate the risks. The materials also indicated the level of safety required of the workers by the parent group. As a result, this activity was also beneficial for the Thai firm.

\section{Conclusions}

1) A questionnaire survey on Japanese-affiliated companies operating in Thailand and Vietnam indicated that all the respondent companies have been engaging in " $5 \mathrm{~S}$ activities" since being founded. The authors conclude that the firms' top management wishes to instill discipline in their employees and make them obey the firms' rules, thereby improving their safety awareness. In addition, "Examinations of accidents", "KY activities", and "Safety proposal activity" were adopted by nearly $80 \%$ of the companies; these activities were also effective. These activities should all be adopted by new factories operating in developing countries.

2) The results of the actions to improve safety at Hidaka's Thai factory are as follows.

Initially, the target was to improve the safety at the Thai subsidiary by raising the level of the employees' safety awareness to parity with that of the employees at the Japanese parent company. It was important not to overwhelm them with activities while doing this. Instead, the Thai subsidiary introduced one safety activity at a time according to the order of importance and moved forward only after determining the extent of their comprehension and achievement.

The safety activities introduced first were $5 \mathrm{~S}$ and $\mathrm{KY}$, with particular emphasis on $5 \mathrm{~S}$. The employees created 5S conditions through [arrangement], [putting into order], [cleaning], [sanitation], and [being well-bred]. Hidaka believed that these $5 \mathrm{~S}$ activities were the foundation of all production work as well as safety. The concepts and methods of KYT were also taught. The group method of KYT was used to generate group outcomes. This activity taught employees that risks may be present anyplace and in any situation and that they can reduce this risk through KY. The firm also developed prevention plans for accidents similar to those that had occurred at the Japanese parent company.

As a result of the above activities, the safety level of the Thai workers reached between $70 \%$ and $80 \%$ of that of the Japanese workers. However, differences between the Japanese and Thai workers' fixation ratios suggest that safety education must be differently approached in Thailand, where workers would leave the firm after having been educated at a considerable cost in time and money; new workers constantly needed to be educated. This problem is less likely to exist in Japan. The solution may be to educate a Thai "key" person and train him or her to educate new employees. However, only one loss-time accident and only two or three no-loss-time accidents would occur at the Thai factory each year, indicating that the workers' safety awareness had grown and the number of accidents had decreased a great deal since the firm had begun. Therefore, if the Thai subsidiary 
accomplishes one more step forward, it will be close to its first target: raising the employees' safety awareness to the same level as that of the Japanese parent company.

\section{Acknowledgements}

The authors wish to express their gratitude to several significant contributors to this paper. First, we would like to thank all of the members of the Thai subsidiary who tried to improve their safety practices. Second, we would like to thank the members of our parent company, who supported the management of the Thai subsidiary. In particular, we must say many thanks to Mr. Nobukata Ochiai, the first president of the company. Finally, we sincerely thank the top managements of the Thai and Vietnamese companies who answered our questionnaire.

\section{References}

[1] Duijm, N.J., Fievez, C., Gerbec, M., Hauptmanns, U. and Konstandinidou, M. (2008) Management of Health, Safety and Environment in Process Industry. Safety Science, 46, 908-920. http://dx.doi.org/10.1016/j.ssci.2007.11.003

[2] Cox, S. and Cox, T. (1991) The Structure of Employee Attitudes to Safety: A European Example. Work \& Stress, 5, 93-106. http://dx.doi.org/10.1080/02678379108257007

[3] Matsuzaki, H. and Yamana, Y. (2005) 5S, Kaizen and English Expression. Sansyusya, Tokyo.

[4] Rahman, M.N.A., Khamis, N.K., Zain, R.M., Deros, B.M. and Mahmood, W.H.W. (2010) Implementation of 5S Practice in the Manufacturing Companies: A Case Study. American Journal of Applied Sciences, 7, 1182-1189. http://dx.doi.org/10.3844/ajassp.2010.1182.1189

[5] Tanabe, H. (2004) Beginner’s Book of KY Prediction. Japan Industrial Safety and Health Association, Tokyo.

[6] Tanabe, H. (2004) Training of KY Prediction. Japan Industrial Safety and Health Association, Tokyo.

[7] Cheyne, A., Cox, S., Oliver, A. and Tomas, J.M. (1998) Modeling Safety Climate in the Prediction of Level of Safety Activity. Work and Stress, 12, 255-271. http://dx.doi.org/10.1080/02678379808256865

[8] Guldenmund, F.W. (2000) The Nature of Safety Culture: A Review of Theory and Research. Safety Science, 34, 215257. http://dx.doi.org/10.1016/S0925-7535(00)00014-X

[9] Dea, A.O. and Fin, R. (2001) Site Manager and Safety Leadership in the Offshore Oil and Gas Industry. Safety Science, 37, 39-57. http://dx.doi.org/10.1016/S0925-7535(00)00049-7

[10] Pousette, A., Larsson, S. and Tomer, M. (2008) Safety Climate Cross-Validation, Strength and Prediction of Safety Behavior. Safety Science, 46, 398-404. http://dx.doi.org/10.1016/j.ssci.2007.06.016

[11] Hidaka, A., Izato, Y. and Miyake, A. (2014) Lessons Learned from Recent Accidents in the Chemical Industry in Japan. Open Journal of Safety Science and Technology, 4, 145-156. http://dx.doi.org/10.4236/ojsst.2014.43016 
Scientific Research Publishing (SCIRP) is one of the largest Open Access journal publishers. It is currently publishing more than 200 open access, online, peer-reviewed journals covering a wide range of academic disciplines. SCIRP serves the worldwide academic communities and contributes to the progress and application of science with its publication.

Other selected journals from SCIRP are listed as below. Submit your manuscript to us via either submit@scirp.org or Online Submission Portal.
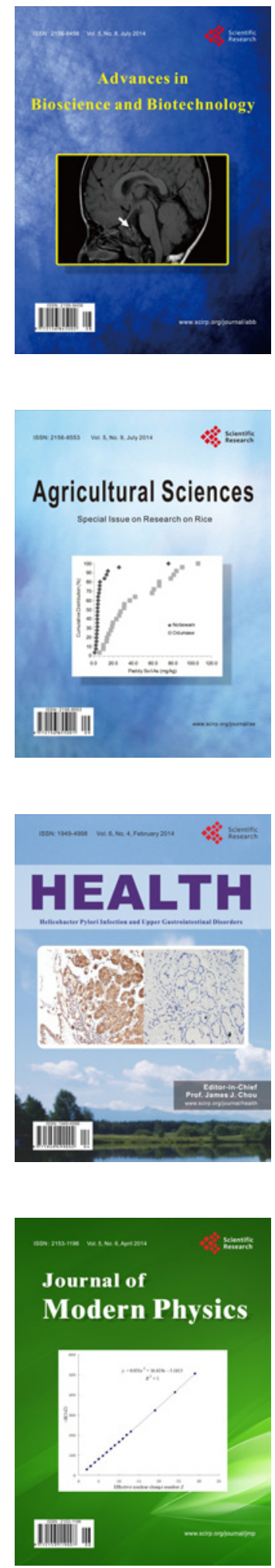
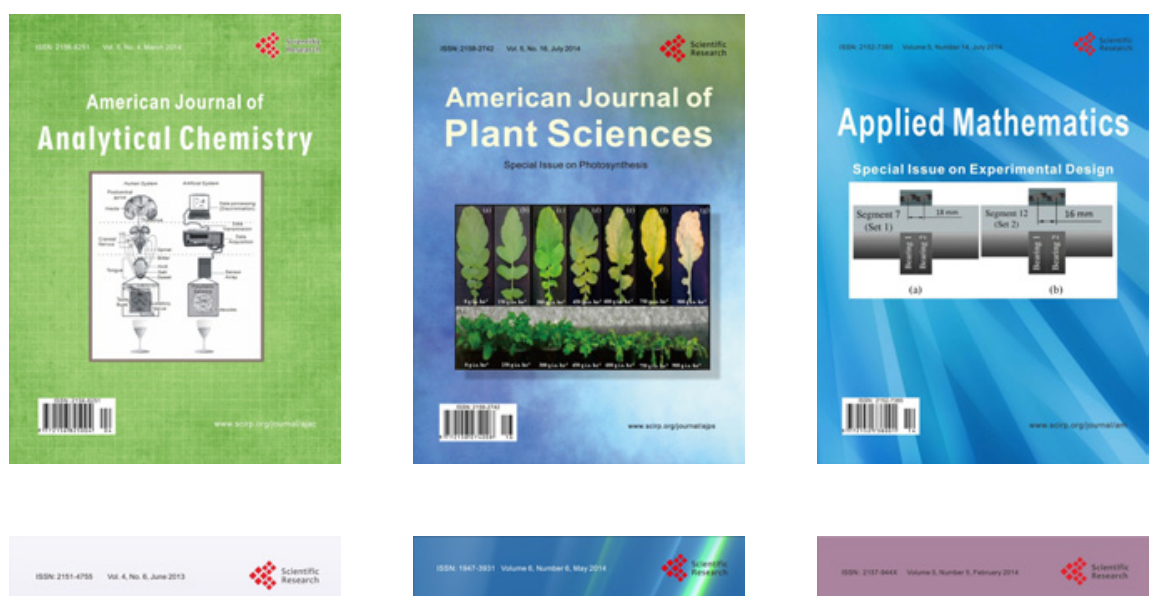

Creative Education
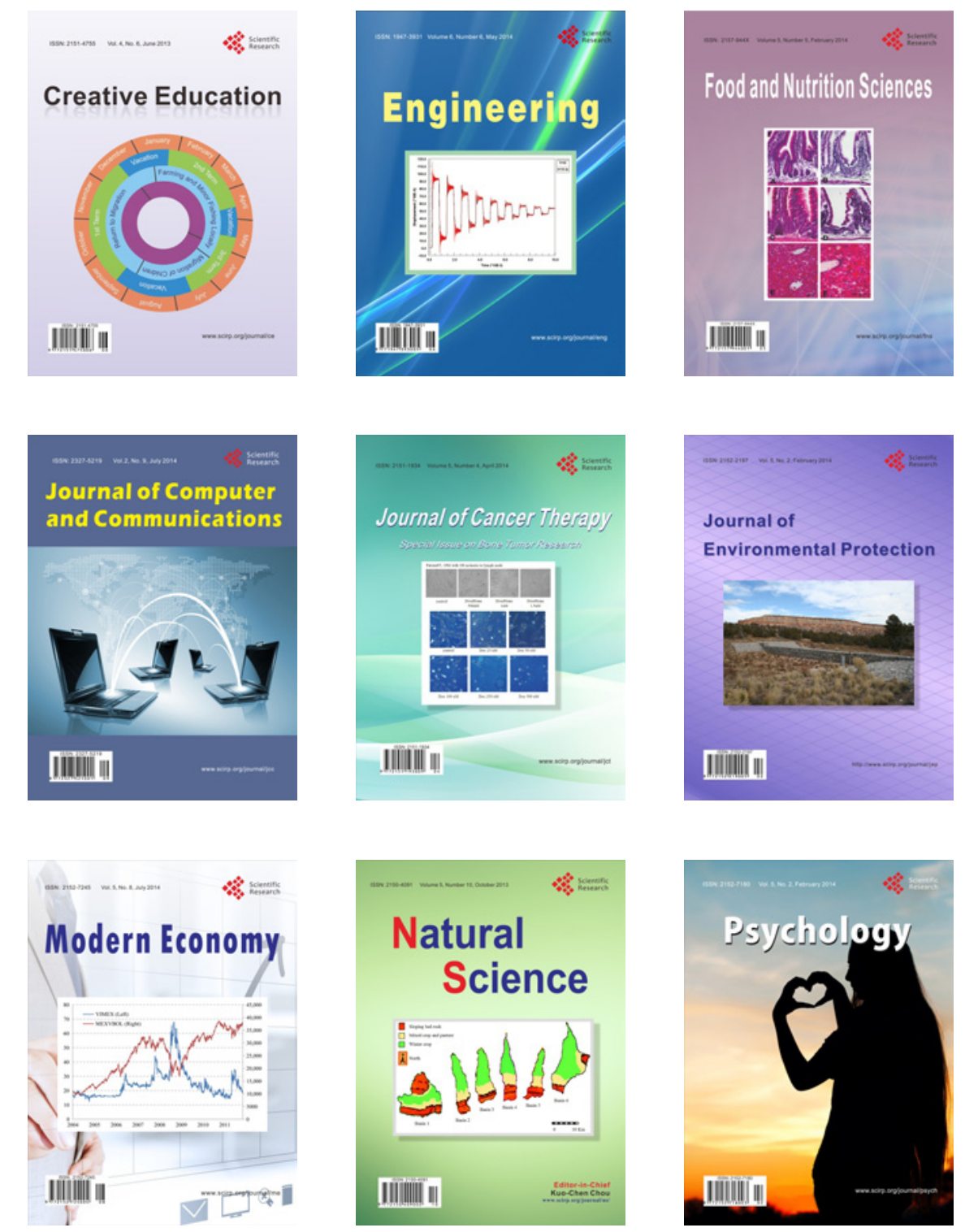